\title{
Prevailing narratives versus reality of a small and medium town decline in a CEE country
}

\author{
Martin Bod'a $^{1,2,3}$ (D) David Cole ${ }^{1}$ (D) Mária Murray Svidroňová ${ }^{1,4}$ (D) \\ Jolana Gubalová1 ${ }^{[D}$
}

Received: 20 October 2020 / Revised: 1 March 2021 / Accepted: 29 May 2021 /

Published online: 5 July 2021

๑ The Author(s), under exclusive licence to Springer-Verlag GmbH Germany, part of Springer Nature 2021

\begin{abstract}
It is a common narrative that small and medium towns of formerly socialist countries of Central and Eastern Europe (CEE) are suffering a substantial decline due to better offerings in bigger metropolitan areas. Focused on Slovakia, this paper presents a methodology for assessing the future viability of small and medium towns, considering different socio-economic, infrastructural, and demographic aspects capturing their desirability. The proposed methodology aggregates different aspects into attributes by means of a data envelopment analysis model with common set of weights without explicit inputs (CSW DEA-WEI), and then converts these attributes into scores in the fashion of a multiple criteria decision analysis (MCDA). The methodology offers a new perspective for rating the viability and sustainability of small and medium towns in the CEE region, and is amenable to adaptations elsewhere. Contrary to popular belief, it is found that small and medium towns remain attractive for life.
\end{abstract}

Keywords Small and medium towns · Hinterlands · Rural and urban life $\cdot$ CSW DEA-WEI model $\cdot$ MCDA

\section{Introduction}

Throughout much of the world, cities are growing at an unprecedented rate presenting major challenges for national and local governmental officials (Marans, 2015). World statistics compiled by the United Nations (2018) inform that there are currently 548 cities around the world with a population of over 1 million. Global trends point to a continuation of this trend towards mass agglomeration. It is estimated that $55.3 \%$ of the world's population currently live in an urban settlement with a

Martin Bod'a

martin.boda@outlook.com

Extended author information available on the last page of the article 
projected $60 \%$ of people who are expected to live in settlements of at least half a million by 2030 .

As the trends point to ever more mass agglomeration, it is important not to lump all continents of the world into one group as every part of the world has its own unique conditions. In the European Union (EU), for example, there are 93 urban areas with a population of over 500,000 (Demographia, 2020) in contrast to a population of 513.5 million inhabitants (as reported by Eurostat for 2019). Nonetheless, most of the new members of the EU are countries that were part of the former Soviet bloc. All of these countries have undergone long and painful transformations from a command economy to capitalism in order to start "catching up" to their western counter-parts. This meant the adoption of a technological-led post-modernism where, in terms of geographical development, urban centres became the launching point for all things new within a country, especially capital cities. The idea of staying in a small town far away from the big city has meant placing limits on opportunities and success. For example, Yin et al. (2019) point out that a world with large disparities in development between rural and urban areas could never achieve sustainable development goals. This observation is based on problems with which urban areas are overwhelmed, such as high living cost, traffic, air pollution, and demand for industry upgrading; meanwhile rural areas have to cope with scarce resources, lower social trust, and limited human capital. This tension between urban and rural life leads to a prevalent narrative of dismissal of small town vitality, which was motivation for the research presented in this paper: to challenge the prevailing narratives and bring inputs for regional policy planning.

This paper is concerned with the validity of the popular narrative that small and medium towns are on the decline due to the better offerings in bigger metropolitan areas with a focus on Slovakia. Slovakia's current state is still shaped by its socialist past, which makes Slovakia a typical post-socialist CEE country, after the change of regimes, lengthy public administration reforms and the creation of new municipalities with their own competencies. The paper develops a methodology for assessing a town's viability for life, which is transferable not only to other CEE countries that had to face a similar socialist past and public administrative reforms, but its elements are fairly general and applicable to other countries. In this methodology, a municipality is evaluated by various partial indicators depicting different aspects of its sustainability and prospects for life that are classified into eight generic attributes capturing demography, economy and social infrastructure. In the first instance, partial indicators are aggregated into attributes in the benefit-of-the-doubt framework of data envelopment analysis (DEA) by dint of a model constrained to a common set of weights and without explicit inputs (CSW DEA-WEI). Then, an approach to multiple criteria decision analysis (MCDA) is used to transform the eight attributes into scores by searching through the space of all combinations that are admissible under plausible a priori restrictions. The methodology produces a ranking of municipalities in a selected region of Slovakia, and its soundness is demonstrated against the existing conventional classification of Slovak municipalities, which is apparently outdated. The proposed framework exhibits several novel features when juxtaposed to the extant methods devised for assessing municipalities and for ranking them on the axis of rural and urban life. First, in order to obtain more trustworthy results, 
it exploits in a coherent manner two different popular benchmarking methods (i.e., DEA and MCDA). Second, as opposed to common practice in DEA, it stresses the need to apply a same set of weights to all municipalities for the sake of better comparability. Third, it takes a cautious approach to MCDA following the guidelines of stochastic multi-criteria acceptability analysis (SMAA) so as to render the judgemental input benevolent and limit it to expressing only a priori restrictions on desirability of attributes. Fourth, in contrast to typical deterministic assessments, it emphasizes simultaneously that the ranking results must be augmented adequately with a sensitivity analysis, conducted here by means of Monte Carlo simulations.

The effort is motivated by inquiries into the validity of the described narrative that small and medium towns in CEE countries are on the decline and have little to offer to its inhabitants. It is important to note that after the public administration reforms, the settlement structure in Slovakia is very fragmented. Municipalities vary in size greatly from the largest ones to those counting less than 100 inhabitants in the countryside (Klimovský et al. 2014). Under these circumstances, the paper does not apply the EU definition for a small town with 5,000 inhabitants, but a small town is understood here as a town with population between 1,000 and 10,000, and a medium town as the one with population between 10,001 and 80,000 .

The paper is organized in into 5 more sections. Section 2 is a literature review, and Sect. 3 makes short notes explaining the motivation. Sections 4 and 5 present the methodology and results, respectively. Section 6 completes by discussing the results and drawing implications.

\section{Literature review}

When discussing living preferences, it is a convenient argument to resort to the advantages that big cities offer. There are quite a few salient arguments for mass agglomeration, which create a prevailing narrative of big cities survival over the small and medium ones. Long ago, Marshall (1920) noted the evolution of agglomerated areas. Firstly, firms need to locate near suppliers or customers to save shipping costs; secondly, clustering of like-minded business help to stimulate innovation within a specific field; and finally the intellectual spill-over helps create new businesses, thus adding to the agglomeration. The research by Giannone (2017) on American cities found that regional convergence, where poorer areas become wealthier, began to stall in the 1980s. Krugman (2017) cited the gambler's ruin, where smaller players (towns and villages) will eventually lose out to a larger player, i.e., a smaller municipality will suffer a greater loss if a business fails, unlike a larger city. As such, in modern society, agglomeration becomes economic destiny with all other territories relegated to insignificance or focusing on the primary sector and low value-added production and thus suffering a substantial decline.Three salient facts bring into question whether rampant urbanism is economically viable in the long-term, especially for Europe: 
1) A German study by the Federal Institute for Research on Building, Urban Affairs, and Spatial Development (2013) has found that most all city regions are growing, in CEE as well, while half of Europeans live in shrinking regions. Shrinking regions exist in nearly all countries.

2) According to the 'State of Housing in the EU' by the EU Urban Agenda Housing Partnership (Pittini et al. 2017), housing has become a problem due to the prices (buying a house is the highest expenditure for Europeans, house prices are growing faster than income in most member states, while inequality and housing exclusion are mutually reinforcing).

3) With recent political movements in the EU (e.g. Brexit, the yellow-vest movement in France, and the success of non-mainstream parties in many EU countries), a backlash can be seen with the limits of what society is willing to accept. Rural dwellers have found their voice in the ballot box.

It needs to be said that there is too small a focus on rural areas in general where most public economists and sociologists prefer the challenge of big city solutions to the ever-growing metropolis. When rural development is mentioned, it is often confused with notions of agricultural development, e.g. the technological advances allowing farm work to be done by fewer people (Torre and Wallet, 2016). If the notion of rural areas transcends beyond agro-production, then the rural regions can be seen as providing a wider range of amenities such as biodiversity, demand for space, landscape, leisure, etc. (Vollet, 2002). The rural areas are then characterized as having a loss of knowledge capital as well as a loss of population. Easterlin et al. (2011) proved that in terms of life satisfaction there are at low levels of economic development substantial gaps favoring urban over rural areas in income, education, and occupational structure, and consequently a large excess of urban over rural life satisfaction, despite important urban problems of pollution, congestion, etc. At more advanced levels, these differentials tend to disappear, and rural areas approach or exceed urban areas.

When looking beyond just mere economic considerations, a case must be made for growing up in a small town. Anthropologist and sociologist Howell (2013) noted that younger people in smaller towns from different economic backgrounds had a better chance of getting to know doctors, lawyers and other prominent people. For the upper class, there is a sense of being a big fish in a small pond. In their study of small towns in the US, Carr and Kefalas (2009) found that young people have a sense of "being a part of something bigger than themselves." A Gallup poll of 1,499 random sampled adults found a big gap between aspiration and reality with $15 \%$ of Americans actually living in towns in rural areas, while $27 \%$ ideally stated that they would like to live there (Newport, 2018).

This was similar to the research by the EU (Eurofound, 2019) which discovered that a higher proportion of rural residents than urban residents strongly feel a sense of belonging in their community - the negatives of rural living include poor quality public transport, problems with health care access, and a high level of social exclusion among the older generation. On the other hand, Noronha et al. (2013) have found old conceptions of rural as being a place lacking in amenities and where people are less educated is fast fading. Apart from population density and environmental 
amenities, the difference between urban and rural areas in many countries is rapidly vanishing, as the difference in life styles, education, service availability and ICT access is disappearing.

Apart from the above mentioned criteria of (public) transport, age structure, poor health care access and lack of other amenities, other authors assess the viability or sustainability of small and medium towns, e.g. focused on the community satisfaction (Goudy, 1977), improving market based development of small towns (Gaile, 1992) or economic, technological and social factors (Kenyon and Black, 2001). Most authors agree on criteria such as population/demographics, employment opportunities, education access and social capital (Alston, 2002). Sánchez-Zamora et al. (2014) identified the factors that have determined successful territorial dynamics in rural areas of Andalusia during economic expansion periods, using data envelopment analysis. The results highlight how different aspects of economic, human, natural, and social capital such as economic diversification (rural tourism), agriculture (funding, young farmers, organic production), access to services (infrastructures and facilities), demographics (foreign population), natural resources and governance (rural development funding) can drive successful territorial dynamics in rural areas. Marans (2015) examined the culture of sustainability among urban residents monitoring the quality of urban life, using a set of objective indicators (employment rate, education, per capita income, crime statistics, domestic violence, death rate, air quality, residential density, distance to transit stop, availability of grocery shops, vehicle miles travelled) and subjective indicators (perception of crime, of school and health care quality, desire to move, satisfaction with housing and neighbourhood, overall well-being).

In the conditions of Slovakia, the only studies tackling this issue are geographical studies dividing the municipalities based on economic, technological and social factors. For example, Gajdoš et al. (2009) in their study on socio-spatial aspects of urban-rural complementarity relied heavily on factors such as municipality size, unemployment rate, number of job seekers, number of people working in industry, agriculture and services, education, number of flats, number of commuters, birthrate, migration and age structure. The resultant taxonomy, conventionally adopted in classification of Slovak towns, is presented in Table 1 and ranks municipalities through nine ordinal (disjunctive) categories in a descending manner by their attractiveness and prospects. In consequence, categories 4 to 9 are deemed as marginalized communities. The classification by Gajdoš et al. (2009) is obviously outdated not only from a sociological viewpoint, but also economically, since it places great emphasis on industrial and agricultural activities whilst ignoring developments in tertiary and quaternary economic sectors. In addition, being more than a decade old, this classification overlooks the viability of municipalities, which makes it not very accurate in quickly changing trends.

Another study for Slovakia, Buček et al. (2014), is also geographical. It builds on the concept of a network model of spatial organization, which attempts to describe spatial reality better and which focuses on the complementarity of municipalities. Examples of this modelling approach in the past include Meijers (2007), Neal (2011) or Hall et al. (2001). Albeit Buček et al. (2014) considered factors like economic structure and population size, little attention was paid to the 
Table 1 Conventional classification of Slovak towns by Gajdoš et al. (2009)

\begin{tabular}{ll}
\hline Category & Description and additional characterization \\
\hline 1 & Urban and urban-like centres (cities and towns, high population density, low unemploy- \\
ment, highly educated population, high economic activity) \\
Commuter communities (areas in the vicinity of category 1, perhaps suburban, intense \\
house construction, used for residence whilst economic activity located elsewhere) \\
Villages with above-average employment in industry (high industrial economic activity, \\
low unemployment relative to equally-sized villages) \\
Demographically old industrial villages full of unoccupied buildings (dead industrial \\
activity, idle industrial premises, numerous empty flats and houses) \\
Villages with above-average employment in agriculture (villages with active agricultural \\
activity, high job occupancy rates in agriculture, stable population size) \\
Agriculturally dominant villages with a falling population (traditional agricultural villages \\
with still active agricultural activity, but facing a population decrease) \\
Villages with high unemployment, low natality and a low-educated population (dead \\
industrial and agricultural activity, poorly-educated population, low mobility) \\
Villages with high natality and populated predominantly by inhabitants of pre-produc- \\
tive age (dead industrial and agricultural activity, large number of children, high birth-rates, \\
poorly-educated population, high unemployment) \\
Declining localities (small population size and still shrinking, dead industrial and agricultural \\
activity, mainly older and aged population) \\
a
\end{tabular}

viability of municipalities as the study is focused on human geography, not on regional development.

When it comes to measuring the viability of small and medium towns for life, the paper uses a case study of Slovakia. In this regard, it must be said that Slovakia can only claim to have one metropolitan area as its other cities are considered medium and small urban areas. The country contains two larger cities on opposite ends of the country. The capital city, Bratislava, plays the role of governmental, financial, and gateway centre to the rest of the country. In addition, with two major car companies located within the commuter zone, it also plays host to automobile manufacturing.

A critical aspect of living in a Slovak small and medium town is the presence of a Romany population, which is rather avoided in the abovementioned Slovak studies since this topic is very sensitive and might feel discriminatory. However, in the eyes of many, this is a factor to consider when deciding on their residence and as such it influences the attractiveness and viability of municipalities. The authors distance themselves from any bias, but they map the Slovak reality in their "true colours". After the fall of socialism, the Roma community was going to be the first to be marginalized, the first to be deprived of jobs, and the first to be gentrified out of "normal" communities. Since 1991, there has been a high level of migration of Romanies from integrated communities to separate and concentrated communities (Matlovičová et al. 2012). These isolated communities then became an obstacle to gainful employment when the period of high unemployment began to subside. The perception of Roma poverty and substandard housing conditions leads inevitably to bias and harmful generalization prompting an avoidance mentality among the Slovak major community (Růžička, 2012). 
In the hope of offering more structured insights into factors that literature finds of relevance in assessing attractiveness of municipal life, Appendix A enumerates a variety of studies and lists the factors upon which these studies drew. Most of the studies in the table of Appendix A are mentioned in this literature review, and upon perusing the table it should be borne in mind that the goal or target of the catalogued studies differed (i.e., it ranged from measuring a particular aspect of quality of life to making a comprehensive assessment of sustainability and potential). In addition, every study had its own geographical focus, and tailored the assortment of factors accordingly by highlighting the troubles and particularities of that region. These aspects and factors blended with Slovak specific conditions were followed in the choice of the eight criteria represented in the analysis to assess a small and medium town's viability for life. They are, however, explained further in Sect. 4 concerned with methodological issues.

\section{Motivation}

The motivation to challenge the generally accepted paradigm that life in a city (or a large town) for the contemporary generation is more attractive than life in a small or medium town did not arise as an end in itself. Actually, the intention to analyze the viability of a small and medium town in Slovakia, a typical post-socialist country, sprouted out of a survey organized as part of long-term research. A questionnaire was sent in 2018-2019 to mayors of all 115 municipalities of over 1000 inhabitants in the Banská Bystrica region. The region was chosen for its size, its central location, geographical variety, and economic conditions that range from prosperous to impoverished, and thus represents a region with typical conditions for small and medium towns. There are only 115 municipalities with a population of over 1,000 residents out of 516 municipalities in the region; and these municipalities amount to $76.28 \%$ of the population in the region.

The mayors were presented with a survey concerning the attractiveness of their community to each municipality. A summary of their answers is given in Table 2. Of the 115 municipalities, there were 58 responses from the mayor's office with a response rate of $50.43 \%$. A total of 17 responses were collected from municipalities in the commuter zone of the two largest towns in the region, Banská Bystrica and Zvolen (henceforth referred to as $\mathrm{BB} / \mathrm{ZV}$ ), and 41 from were from hinterland communities. The mayors were asked about the advantages and disadvantages of the communities, with a focus more on hard infrastructure and less on economic activities related to work and employment. When combining hard infrastructure with soft infrastructure (e.g. demographic indicators, social structure, and culture) as well as natural and geographical elements, the creative potential of a territory could lead to the more desirable intangible elements such as creativity, symbolic value, diversity, authenticity, image, and atmosphere (Romein and Trip, 2012). This will in turn lead to local economic growth.

Apart from high unemployment, the two sorest issues were bad roads and a large Romany population whose importance is probably somewhat underestimated for two reasons. One reason is the doctrine of political correctness and imputed fears 
Table 2 Advantages/disadvantages of municipalities in the eyes of their mayors

\begin{tabular}{lll}
\hline Advantages & Rank & Hinterland \\
\cline { 2 - 3 } & BB/ZV & 4 \\
\hline Good location (close to the city, enough jobs) & 1 & 2 \\
Good infrastructure (public transport, roads, internet) & 2 & 3 \\
Good services (schools, health care, shops, entertainment, etc.) & 3 & 1 \\
Beautiful nature & 4 & 5 \\
Nice architecture & 7 & 6 \\
Possibility to buy real estate as a good price & 5 & 7 \\
Good social and community life & 6 & 1 \\
Disadvantages & & 2 \\
Few job opportunities, high unemployment in municipalities & 1 & 4 \\
Social Romany problems & 2 & 3 \\
Far from a bigger city & NA & 5 \\
Bad roads & NA & 6 \\
No room for development & NA & NA \\
Lack of infrastructure & & 5 \\
\hline
\end{tabular}

Other problems mentioned by the mayors of hinterland municipalities were reluctance to increase population, missing sewers, political party interference

of racist attitudes. The other is that most answers were obtained from municipalities with a small proportion of the Romany population. Nonetheless, the factors that were identified in this manner guided the selection of attributes in the construction of numerical ratings to assess the viability of a municipality for life.

\section{Methodology}

The survey whose results were presented in the preceding text was qualitative in nature and presents more of a snapshot of prevailing attitudes towards small municipalities than actual opinions of those who can choose their future life narrative. A credible assessment of the small town perspective for living should be derived from a numerical rating of a town's future prospect. Such a rating that seeks to capture sustainable and attractive features of small towns for life is developed here, confined to the present case study of Slovak municipalities. Considering that any decision to favour one town over another with respect to desirability and viability must be footed upon numerous criteria, an approach to multiple-criteria data analysis (MCDA) was adopted. For every municipality a total of 8 main areas of criteria were identified and measured typically by several metrics that were aggregated into attributes, converted into utilities, weighted and averaged. The outcome was the average utilities of living in municipalities normalized in the interval $[0,1]$. Three special methodological choices were associated therewith: First, different metrics were aggregated into an attribute (represented often by a composite index) in a framework of data envelopment analysis (DEA) by using a CSS DEA-WEI (common-set of weights 
DEA without explicit inputs) model. Second, spatial proximity of other municipalities was taken into consideration wherever appropriate. Third, no specific weighting scheme or forms of utility functions was introduced for different attributes, but these were simulated in the spirit of stochastic multi-criteria acceptability analysis (SMAA).

Under the monicker "benefit of the doubt" (BoD), DEA models have been successfully employed to set up composite indicators in order to measure quality of urban life (Morais and Camanho, 2011), to assess different kinds of economic policies (Cherchye et al. 2007a, b, 2008), to compare health systems (Shwartz et al. 2016; Cylus et al. 2017), or to construct indices of human development, tourism competitiveness, digital access (Despotis, 2005a, 2005b; Martin et al. 2017; Gaaloul and Kahlfallah, 2014). The BoD approach is expounded as an entrenched method in the handbook of OECD (2008) or the survey by Grupp and Schubert (2010), but in operations research this modelling approach goes familiar as DEA without explicit inputs (DEA-WEI) as it posits uniform (or no) inputs to all units under assessment alongside a full variety of outputs (Liu et al. 2011; Yang et al. 2014). With such an input-output specification and with the use of linear programming, BoD / DEA-WEI seeks for every unit a unit-specific favourable set of weights that satisfy certain optimality criteria. The tendency to attain extreme scenarios is controlled by imposing a priori weight restrictions (e.g., Cherchye et al. 2007a, b, 2008) or by demanding that all units are evaluated by means of a common set of weights (CSW) to suppress variations in the weights (Despotis, 2005a, 2005b; Hatefi and Torabi, 2010; Morais and Camanho, 2011). Out of the various DEA models operating under CSW (e.g., Liu and Peng, 2008; Davoodi and Rezai, 2012; Yekta et al. 2018), this analysis builds on a recent CSW method by Yekta et al. (2018) that is combined here with a traditional DEA-WEI model. The resulting model is addressed here as CSW DEA-WEI and exploits to the full extent the features of both components. Suppose that there are $n$ units (in the present case, municipalities) that are characterized by $s$ indicators with preferably high values and with arbitrary measurement units (i.e., they need not be normalized, but must be sought to be maximized). Denote by $\mathbf{y}^{i}=\left(y_{1}^{i}, \ldots, y_{s}^{i}\right)^{\prime}$ the observed vector of the indicators for unit $i$ (with $i \in\{1, \ldots, n\}$ ). A traditional BoD / DEA-WEI model requires solving successively for each unit $i$ the following linear program:

$$
\begin{aligned}
C I^{i}=\max _{u_{1}, \ldots, u_{s}} \sum_{r=1}^{r=s} u_{r} y_{r}^{i} & \\
\text { subject to } & (\mathrm{C} 1) \sum_{r=1}^{r=s} u_{r} y_{r}^{o} \leq 1, o \in\{1, \ldots, n\}, \\
& (\mathrm{C} 2) \delta_{r}^{-} \leq u_{r} y_{r}^{o} / \sum_{r=1}^{r=s} u_{r} y_{r}^{o} \leq \delta_{r}^{+}, r \in\{1, \ldots, s\}, o \in\{1, \ldots, n\}, \\
& \text { (C3) } u_{r} \geq 0, r \in\{1, \ldots, s\} .
\end{aligned}
$$

By dint of suitably specified upper and lower bounds $\delta_{r}^{-}, \delta_{r}^{+}>0$, condition (C2) in program (1) regulates the contribution of indicator $r$ into the value of the composite indicator. Nonetheless, program (1) is applied independently to all units and identifies thus, as a rule, different sets of optimized weights, which is at variance with the logic of meaningful and reasonable comparisons. By dropping 
condition (C2) and applying the approach of Yekta et al. (2018), a CSS DEAWEI model ensues whose advantage is that it generates strictly positive weights and prevents weight dissimilarity. The model is given by this non-linear program that should be run once for all units:

$$
\begin{aligned}
& \min _{d^{1}, \ldots, d^{n}, u_{1}, \ldots, u_{s}, \omega} \omega^{-1} \sum_{o=1}^{o=n} d^{o} \\
& \text { subject to } \sum_{r=1}^{r=s} u_{r} y_{r}^{o}+d^{o}=1, o \in\{1, \ldots, n\}, \\
& 0 \leq \omega \leq u_{r}^{\#} \leq 1, r \in\{1, \ldots, s\},
\end{aligned}
$$

whose linear format takes form

$$
\begin{aligned}
& \min _{d^{1 \#}, \ldots, d^{n \#}, u_{1}^{\#}, \ldots, u_{s}^{\#}, \varpi} \sum_{o=1}^{o=s} d^{o \#} \\
& \text { subject to } \sum_{r=1}^{r=s} u_{r}^{\#} y_{r}^{o}+d^{o \#}=\varpi, o \in\{1, \ldots, n\}, \\
& 1 \leq u_{r}^{\#} \leq \varpi, r \in\{1, \ldots, s\} .
\end{aligned}
$$

The common set of weights is retrieved from the optimal solution of (3) by plugging it into the detransformation formula $u_{r}=u_{r}^{\#} / \varpi(r \in\{1, \ldots, s\})$. The value of the composite indicator is then obtained for unit $i$ as a linear combination $C I^{i}=\sum_{r} u_{r} y_{r}^{i}$ evaluated at the detransformed optimal common weights.

Most aspects of urban or rural life are not symptomatic for a specific closed location, but descend also from the location's surrounding. In other words, the viability of a certain municipality for life is not affected only by the features with which the municipality itself abounds, but also by the features that are found in other spatially neighbouring locations. In most cases, as appropriate, attributes (i.e., composite indices or standalone metrics) were averaged by spatial weights to take into account not only the value of a particular attribute, but also the attributes of other municipalities, weighted down by their spatial distance. To this effect, spatial weights are introduced for attributes and derived from Euclidean (i.e., "as the crow flies") distances between units. If $d_{i j}$ is the straight-line distance in $\mathrm{km}$ from unit $i$ to unit $j$, then the usual definition for spatial weights is $w_{i j}=d_{i j}^{-1}$ for $i, j \in\{1, \ldots, n\}$ such that $i \neq j$, and $w_{i i}=1$ for $i \in\{1, \ldots, n\}$ (cf., e.g., Anselin, 1988, p. 19; Shekar and Xiong, 2008, p. 1113). The spatially averaged attribute then arises as $\bar{A}^{i}=\sum_{j} w_{i j} A^{j} / \sum_{j} w_{i j}$ for unit $i(i \in\{1, \ldots, n\})$. This particular definition amounts to using a row standardized spatial weight matrix (cf., e.g., Arbia, 2014, pp. 28-29).

Finally, since the knowledge about the actual utility of attributes to an individual is in the present context limited, an approach based upon unspecified utility functions and priorities assigning significance to the attributes is adopted. The treatment goes along the lines of stochastic multi-criteria acceptability analysis (SMAA) developed by Lahdelma et al. (1998) or non-numeric, non-exact and non-complete (NNN) information of Hovanov et al. (2009). Hence, the attributes were converted into utilities using most general forms under the approach outlined by Doumpos and Zopounidis (2013, pp. 240-241) except that a balance 
between two different kinds of aggregation of utilities was determined. An equally weighted mixture of the additive and Cobb-Douglas models calculates utility after the expression.

$$
V\left(A_{1}, \ldots, A_{k}\right)=0.50 \sum_{m=1}^{m=k} U_{m}\left(A_{m}\right) v_{m}+0.50 \prod_{m=1}^{m=k} U_{m}\left(A_{m}\right)^{v_{m}}
$$

Formula (4) presumes that there are $k$ attributes $A_{1}, \ldots, A_{k}$ (perhaps spatially weighted) that are converted into individual utilities $U_{1}\left(A_{1}\right), \ldots, U_{k}\left(A_{k}\right)$ and averaged using positive priorities $v_{1}, \ldots, v_{k}$ (whose sum is restricted to unity). With no loss of generality, attributes $A_{1}, \ldots, A_{k}$ are understood as criteria to be maximized and utility functions $U_{1}, \ldots, U_{k}$ take values in the interval $[0,1]$. Whereas the left-hand term is an arithmetic mean (additive model), the right-hand term is a geometric mean (Cobb-Douglas model). The double averaging in the spirit of "the best of two worlds" is recommended by Scholten et al. (2015, p. 249) as it matters what aggregation approach is embraced (Langhans et al. 2014) and it also ameliorates the problem with the so-called rank reversal (Ishizaka and Labib, 2011, p. 14341). Here, the equal weights 0.50 and 0.50 are utilized in formula (4) so as to prefer specifically neither. In the implementation of (4), both individual utility functions and priorities are reconstructed by simulations over an extensive range of possible values and then averaged. A utility function $U_{m}$ for attribute $A_{m}(m \in\{1, \ldots, k\})$ is reconstructed by linear interpolation from observed values of the attribute by mapping the quartile values $a_{m, 0.25}, a_{m, 0.50}, a_{m, 0.75}$ to randomly generated values in $[0,1]$ sorted in ascending order. The worst and best observed values of $A_{m}$ are mapped to 0 and 1, i.e., $U_{m}\left(a_{m, 0}\right) \equiv 0$ and $U_{m}\left(a_{m, 1}\right) \equiv 1$. Here $a_{m, 0}$ and $a_{m, 1}$ are the minimum and maximum observed values of $A_{m}$, respectively. This random generation of utility functions covers a large range of possible subjective evaluations granted that a piece-wise linear approximation suffices. Both convex and concave utility functions are included, albeit they are all strictly monotonic. Priorities $v_{1}, \ldots, v_{k}$ were required to be drawn uniformly from the $(k-1)$-simplex subject to some additional constraints represented by a set $\Xi$. The set $\Xi$ typically contains equality and inequality constraints between priorities. An example is the constraints $\left\{v_{1} \geq 0.25, v_{3}>v_{2}, v_{k} \geq v_{2}\right\}$ whose oral translation is that "attribute $A_{1}$ participates at least by one fourth in the assessment, attribute $A_{3}$ is more significant than attribute $A_{2}$, and attribute $A_{k}$ is at least as important as attribute $A_{2}$ ". The simulations were implemented in accord with the following algorithm:

Step 0 Identify for each attribute $A_{m}, m \in\{1, \ldots, k\}$, its minimum, three quartiles and maximum: $a_{m, 0} a_{m, 0.25}, a_{m, 0.50}, a_{m, 0.75}$ and $a_{m, 1}$.

Repeat for each simulation $b,\{1, \ldots, B\}$, a loop of Steps 1 to 4 :

Step 1 Generate for each attribute $A_{m}, \quad m \in\{1, \ldots, k\}$, three values uniformly distributed in [0,1], sort them in an increasing way, and define an ordered sequence $u_{m, 0}=0, u_{m, 0.25}, u_{m, 0.50}, u_{m, 0.75}, u_{m, 1}=1$. Put $U_{m}\left(a_{m, z}\right) \equiv u_{m, z}$ for $z \in\{0,0.25,0.50,0.75,1\}$, and set up an approximation $U_{m}(a)=u_{m, z}+\left(u_{m, z+0.25}-u_{m, z}\right)\left(a-a_{m, z}\right) /\left(a_{m, z+0.25}-a_{m, z}\right)$ for any middle value $a \in\left(a_{m, z}, a_{m, z+0.25}\right), z \in\{0,0.25,0.50,0.75\}$. 
Step 2 Evaluate observed fixed values of the $k$ attributes for each unit $i$, $i \in\{1, \ldots, n\}$, at $U_{1}, \ldots, U_{k}$ to obtain utilities $U_{1}\left(a_{1}^{i}\right), \ldots, U_{k}\left(a_{k}^{i}\right)$.

Step 3 Generate $k$ random non-random priorities $v_{1}, \ldots, v_{k}$ from the symmetric Dirichlet distribution subject to the constraints in $\Xi$ (generation is repeated until the conditions in $\Xi$ are met, which is but the rejection method).

Step 4 Using formula (4) determine for each unit $i, i \in\{1, \ldots, n\}$, the double averaged multi-attribute utility $V^{i}=V\left(a_{1}^{i}, \ldots, a_{k}^{i}\right)=0.50 \sum_{m}\left[U_{m}\left(a_{m}^{i}\right) v_{m}\right]$ $+0.50 \prod_{m}\left[U_{m}\left(a_{m}^{i}\right)^{v_{m}}\right]$.

The result of Steps 1 to 4 is for each unit $i, i \in\{1, \ldots, n\}$, as many as $B$ evaluation scenarios $\left.V^{i, 1}, \ldots, V^{i, B}\right)$ that are finally summarized in Step 5:

Step 5 Calculate an average utility across all simulation $\operatorname{runs} \operatorname{av}\left(V^{i}\right)=B^{-1} \sum_{b} V^{i, B}$ and its standard deviation $\operatorname{sd}\left(V^{i}\right)=\left[B^{-1} \sum_{b}\left(V^{i, B}-\operatorname{av}\left(V^{i}\right)\right)^{2}\right]^{0.50}$ as a measure of uncertainty.

Based on the literature review and the motivation provided in Sect. 2, eight general aspects important for life in Slovakia are accounted for in the definition of comparable scores. The analysis is again focused on the 115 municipalities with over 1000 inhabitants in the Banská Bystrica region, and explains measurable aspects in these areas: population structure [PS], unemployment [Un], concentration of the Romany population [RC], road accessibility [Rd], availability of shopping opportunities [Sh], availability of health care [HC], availability of educational facilities [Sc], availability cultural amenities $[\mathrm{Cu}]$. An insight into the structure of these 8 viability attributes is given in Table 3 that reveals that most of the factors are assembled of different partial metrics. The data for these metrics were mostly extracted from "DataCube.", a public database of the Statistical Office of the Slovak Republic (http://datacube.statistics.sk/) in March 2020. Detailed methodological notes are in Appendix B.

Some of popular criteria were not taken under advisement. For instance, the notion of using property tax as an attribute was rejected for the tax burden is too insignificantly low to cause any concern. Also distance to a commuter city was not considered out of fairness as towns are rooted to their location and this is an unalterable aspect. Regional gender imbalance could also be a factor in the viability of a municipality especially in the 25-29 year old age group as this is the most important time period for life decisions, e.g. marriage, entering the labour market. Nonetheless, unlike other CEE countries, Slovakia has a relatively even gender balance. Furthermore, what goes unnoticed in the analysis is also availability of accommodation facilities (hotels) and catering establishments (restaurants, food delivery services), and presence of natural amenities (parks, natural reservations, tourist attractions). The former is not linked with the viability of a town form the adopted point of view, and the latter are discarded from considerations for obvious difficulties associated with measurement.

Although the OECD report on population ageing begins with a caveat that an ageing society presents no threat for urban life purporting that cities populated (densely) by older people are good places for any generation (OECD, 2015, p. 3), this is perhaps true for large metropolitan centres with a potent corporate sector and a strong pulse of life backed up with numerous social conveniences. For a typical 
Table 3 Components of the viability attributes and methods of their aggregation

Components of viability attributes

[PS] Population structure

(i.) Economic dependency ratio, (ii.) rate of change in the ratio of \# persons aged 40 years at most to \# persons aged more than 40 years-Source of data: DataCube. ${ }^{1)}$

\section{[Un] Unemployment}

Ratio of \# registered job seekers to total population-Source of data: DataCube. ${ }^{2)}$

\section{[RC] Romany concentration}

Percentage of the Romany population-Source of data: Matlovičová et al. (2012)

\section{[Rd] Roadways}

(i) Distance to a 4-lane expressway, (ii) part of the distance to a 4-lane expressway driven on non-first-class roads, (iii) part of the distance to a 4-lane expressway driven by treacherous roads. Source of data: Google Maps

\section{[Sh] Shopping}

(i) \# of indoor and outdoor shopping malls relative to travelling time in minutes, (ii) \# large discount retailers (Tesco, Lidl, Kaufland, Terno) relative to travelling time in minutesSource of data: Google Maps, Halás et al. (2017)

\section{[HC] Health care}

(i) \# hospitals and policlinics, (ii) \# outpatient facilities of general practitioners for adults, (iii) \# outpatient facilities of physician for children and adolescents, (iv) \# specialized outpatient facilities, (v) \# pharmacies and medical aid supply points, (vi) \# medical emergency service points-Source of data: DataCube. ${ }^{3)}$

\section{[Sc] Schools}

(i.) \# kindergartens, (ii.) \# primary schools, (iii.) \# primary arts schools, (iv.) \# special primary schools, (v.) \# grammar schools, (vi.) \# specialized secondary schools \& conservatories, (vii.) \# youth dormitories, (viii.) \# residence hallsSource of data: DataCube. ${ }^{4)}$

\section{[Cu] Culture}

(i.) \# theatres, (ii) \# galleries, (iii) \# cinemas, (iv) \# libraries, (v) \# museums-Source of data: DataCube. ${ }^{5)}$
Method of aggregation

CSW DEA-WEI (no spatial averaging)

No aggregation \& spatial averaging

No aggregation \& spatial averaging

CSW DEA-WEI (no spatial averaging)

CSW DEA-WEI \& spatial averaging

CSW DEA-WEI \& spatial averaging

CSW DEA-WEI \& spatial averaging

CSW DEA-WEI \& spatial averaging

\footnotetext{
1) Tables om7052rr, om7008rr. Component (ii.) calculated ad hoc from granular data. ${ }^{2)}$ Tables pr5001rr, om7008rr. Calculated from available data. ${ }^{3)}$ Table zd5001rr. ${ }^{4)}$ Tables sv5001rr, sv5002rr, sv5007rr, sv5006rr, sv5003rr, sv5004rr, sv5005rr, sv5009rr, sv5011rr. ${ }^{5)}$ Tables ku5003rr, ku5005rr, ku5008rr, ku5009rr
}

Slovak municipality this is barely true as especially smaller municipalities simply die out (Gajdoš et al. 2009), which is immediately recognizable in a blatant disproportion in the shares of the younger and older generation. Podmanická (2011) draws a dichotomy in the ageing processes of urban and rural municipalities. Smaller villages, especially in rural areas, are at the risk of poverty and with too many elderly dwellers have a less ambitious demand for infrastructure and services and they fall 
into a vicious circle (Michálek, 2005). Gajdoš et al. (2009) define a disappearing village as a municipality with less than 500 inhabitants, which somewhat contrasts with the size criterion adopted for this study, which has 1,000 inhabitants. Some of the analyzed municipalities show sociological symptoms of dying out, and their population make-up is characterized by a high participation of elderly people. In order to identify these characteristics, two metrics are used in conjunction for [PS]. A static metric seeks to capture the proportion of economically inactive population to economically active one. A dynamic metric captures the magnitude of change in the ratio of "young" people to "older" people over a ten-year period. The cut-off of 40 years of age is judgmental.

Similarly as in other countries, in Slovakia access to unemployment is significantly differentiated and spatially heterogeneous, which is merely a consequence of its polycentric municipal structure (Goliaš, 2016, 2017). Some parts of Slovakia are known as "hunger valleys", distinctive for their poverty and lack of employment prospects. In addition to economic impacts (Dietrich and Möller, 2016), unemployment brings about a number of non-economic effects such as unwholesomeness, marital dissolutions, criminality, alcoholism, suicides, and disrupted mental perceptions (Gallie et al. 2001). For this reason, a metric of unemployment (relative to population size) is an indicator that simultaneously surrogates a number of socioeconomic conditions. A measurement of [Un] is appropriate since long-term unemployment is a chronic phenomenon of the Slovak economy (Goliaš, 2017; Lubyová and van Ours, 1999) and is also a proxy for material deprivation that plagues many Slovak households (Bartošová and Želinský, 2013).

It is most unfortunate that the Romany question with issues of Romany avoidance and exclusion is fraught with dangers and misconstrued intentions. Slovakia as well as other CEE countries has not yet found an adequate solution to integrating Romany people into the overall society, either economically or socially. After the fall of Socialism, the Romany community became for several reasons marginalized and gentrified out of socially conformable communities. There is no official measurement of the percentage of the Romany population and their dispersion across Slovakia. Nonetheless, a hazy estimate puts the numbers between $400,000-600,000$ or between $7.4-11 \%$ of the total population, whilst concentrated clustered communities are estimated to be home to $53.5 \%$ of the Romany population with the rest being integrated and living within the major group (Rochovská and Rusnáková 2018). Since 1991 the population of separate and concentrated Romany communities has increased dramatically (Matlovičová et al. 2012). The perception of Romany poverty and substandard housing conditions leads inevitably to an avoidance mentality among the Slovak major community, which is even exacerbated by the fact that the opportunities for spatially marginalized Romany communities, especially in rural areas, to escape the poverty trap is quite limited (Rochovská and Rusnáková 2018; Růžička 2012). The fact that [RC] is considered here is not meant as a slight to the Romany community, but reflects the reality that their concentrated presence in an area is detrimental to those who can choose where they wish to live irrespective of their ethnicity. This attribute is helpful in ascertaining the degree by which a community would be attractive to economic stabilization, i.e., the pull factor of a municipality. With this being said, in no way does this research foster a negative viewpoint. 
The issues of Romany exclusion are so multi-faceted that it is difficult to confine the topic to a unique indicator. Nevertheless, [RC] is represented by the share of the Romany community on a municipality's population. Truthfully, this is scarcely a perfect indicator since it incorporates not only marginalized clustered Romany communities, but also fully assimilated Romany people who are fused amongst the major community. It is probably most appropriate for municipalities with a rural status where Romany communities tend to be more clustered (Matlovičová et al. 2012).

For an individual to live in the hinterlands, readily accessible transportation must be ensured. With only 20 hinterland communities connected to a mainline rail system, the options for transport are mainly dependent on roadways with cars and buses. The highest level for an acceptable roadway would be a four-lane divided highway with limited access i.e., highways and expressways. This expectation of four-lane freedom is also an expectation of business, especially manufacturing. Aside from speed and ease of travel, there is also a safety issue with opposing streams of traffic in comparison to the controlled access divided highways which is always safer. These considerations necessitated that [Rd] was represented the consideration of not only the distance to a four-lane expressway, but also the distance that must be travelled through non-first class roads and treacherous roads. ${ }^{1}$

In Slovakia, there has been a long tradition of local shops with a limited range of products, some of them operated as a retail network (like Jednota, a cooperative, running a network of small food stores all over the country) that serve the needs of commonplace life and are found in every municipality. Modern shopping opportunities started to bloom in the capital city during the transition of the Slovak economy in the 1990s, from where they sprang out to other areas of the country. The first retail outlet to successfully spread across the country was Tesco, followed by Billa, then later Lidl. The first shopping centres in the Banská Bystrica region were in the largest towns of the region, Banská Bystrica in 2007 (another opened in 2017) and Zvolen in 2012. Since this time, other indoor shopping centres and strip centres have proliferated, and a few supermarket chains perished (e.g. Kačka and Carrefour) or were subject to an acquisition or merger (e.g. Hypernova). A once common narrative for living in the hinterland is the lack of shopping opportunities or even a decent meeting place for residents, which is no longer the case as shopping opportunities have gone across the region, especially in district towns. Living in the hinterland used to mean a sacrifice in purchasing opportunities. For Slovaks, this meant travelling to a large urban area such as the capital city for variety. The ubiquitous of chain stores have reached most all parts of the country and this does not include the developing trend of internet shopping.

Specifically three attributes, $[\mathrm{HC}],[\mathrm{Sc}]$ and $[\mathrm{Cu}]$, are associated with less elementary functions and represent the availability of social infrastructure related to quality of life in a particular municipality. To some extent these three factors outstep the basal functions that municipalities are expected to fulfill (i.e., providing a basis for

\footnotetext{
1 A treacherous road is classified as a section of the road that has the three following characteristics: a) steep grades, b) sharp curves (hairpin curves), c) roadways with narrow shoulders and sharp drop-offs. Treacherous roadway distances were calculated where the above characteristics dominated a particular section from a specific point A to a specific point B. Beyond these points, treacherousness is no longer calculated, even if they are the same road.
} 
Table 4 Statistics of the viability attributes normalized to $[0,1]$

\begin{tabular}{lcccccccc}
\hline Descriptive & {$[\mathrm{Ps}]$} & {$[\mathrm{Un}]$} & {$[\mathrm{RC}]$} & {$[\mathrm{Rd}]$} & {$[\mathrm{Sh}]$} & {$[\mathrm{HC}]$} & {$[\mathrm{Sc}]$} & {$[\mathrm{Cu}]$} \\
\hline Mean & 0.518 & 0.771 & 0.571 & 0.725 & 0.331 & 0.071 & 0.074 & 0.106 \\
Standard deviation & 0.165 & 0.154 & 0.203 & 0.258 & 0.214 & 0.113 & 0.114 & 0.106 \\
Median & 0.516 & 0.809 & 0.590 & 0.739 & 0.300 & 0.037 & 0.039 & 0.089 \\
Correlation coefficients & & & & & & & & \\
[Ps] & 1.000 & -0.244 & -0.081 & -0.208 & -0.035 & -0.224 & -0.242 & -0.202 \\
[Un] & -0.244 & 1.000 & 0.724 & 0.678 & 0.536 & 0.207 & 0.236 & 0.376 \\
[RC] & -0.081 & 0.724 & 1.000 & 0.700 & 0.713 & 0.236 & 0.244 & 0.403 \\
[Rd] & -0.208 & 0.678 & 0.700 & 1.000 & 0.576 & 0.187 & 0.212 & 0.337 \\
[Sh] & -0.035 & 0.536 & 0.713 & 0.576 & 1.000 & 0.527 & 0.539 & 0.572 \\
{$[\mathrm{HC}]$} & -0.224 & 0.207 & 0.236 & 0.187 & 0.527 & 1.000 & 0.968 & 0.878 \\
{$[\mathrm{Sc}]$} & -0.242 & 0.236 & 0.244 & 0.212 & 0.539 & 0.968 & 1.000 & 0.918 \\
{$[\mathrm{Cu}]$} & -0.202 & 0.376 & 0.403 & 0.337 & 0.572 & 0.878 & 0.918 & 1.000 \\
\hline
\end{tabular}

economic activities and life as such). Their common denominator in Slovak conditions is the historical stipulation that most facilities that fall under the ambit of these attributes administrated or supervised by the public sector. In Slovakia there are numerous kinds of health care facilities, ranging from hospitals and clinics to specialized outpatient facilities and pharmacies. Health care provision in Slovakia is strictly regulated, e.g., by requirements on a minimal health care network or the reachability of emergency services. Certainly, there is some substitutability of health care providers, but it is imperative for smaller municipalities that a larger municipality within a reasonable distance, which explains why spatial proximity should be considered for [HC]. The system of schools in Slovakia reflects a conventional three-tier structure of education (primary and secondary schools, universities), but the infrastructure encompasses also pre-school facilities (kindergartens and dormitories). Primary schools are mostly found even in smaller municipalities, but most families prefer placing their offspring into a school in a larger, preferably neighbouring municipality. Thus, spatial proximity is a non-negligible factor for [Sc]. Unlike $[\mathrm{HC}]$ and $[\mathrm{Sc}],[\mathrm{Cu}]$ addresses more advanced needs of life in a municipality. There is a high imbalance in cultural amenities in Slovak municipalities as these are concentrated densely in towns. Some categories of cultural facilities (such as theatres and galleries) are absolutely absent in most municipalities, but many are present (such as libraries) in some curtailed form. For each attribute, only numbers of facilities of different types are taken into account at the cost of ignoring their capacities or outputs (e.g. numbers of patients, pupils or visitors), but without distinguishing whether these facilities are run by the public or private sector.

\section{Results}

A snapshot of basic statistical properties of the eight viability attributes constructed in accordance with Table 3 and the accompanying notes is given in Table 4. The minimum and maximums of values are not displayed because each attribute is 
normalized to range from 0 to 1 . The descriptive statistics attest to a presence of heterogeneity amongst the municipalities, even this varies for the attributes. Most municipalities are comparatively well positioned in terms of (low) unemployment, (short) distance to an expressway and (low) Romany concentration (median values and averages are well above 0.50 for [Un], [Rd] and [RC]). On the contrary, there are huge discrepancies regarding spatial availability of shopping opportunities and access to civil infrastructure for health care, education and culture (median values and averages are very low for $[\mathrm{Sh}],[\mathrm{HC}],[\mathrm{Sc}],[\mathrm{Cu}]$ ). The correlation coefficients for [Ps] are very low in terms of their absolute value (and all negative), which indicates that this attribute is fairly unique in terms of the information that it conveys. On the contrary, the correlation coefficients for $[\mathrm{Sh}],[\mathrm{HC}],[\mathrm{Sc}]$ and $[\mathrm{Cu}]$ evince that attributes of civil infrastructure in the municipalities are closely linked and coincide, especially those related to health care, education and culture (correlation coefficients above 0.88). A higher level of similitude is detected between [Un] and [RC]/ $[\mathrm{Rd}]$ as well as between [RC] and [Rd]/[Sh] (correlation coefficients around 0.70). This suggests that municipalities with low Romany concentration are better-off in terms of employment (a high percentage of Romany residents in smaller municipalities are chronically unemployed for several reasons), are situated in the vicinity of an expressway and also have better access to centred shopping opportunities. It is hardly surprising that there also (low) unemployment and (better) access to the state-wide road network are interlinked. This is but in agreement with a general belief that road network accessibility fosters business, which in turn generates employment positions.

The simulation algorithm described in Sect. 3 was implemented with as many as 100,000 simulation runs. The ultimate results with 100,000 simulations were even qualitatively indistinguishable (with differences mostly after two decimal places) from the results produced by 10,000 simulations, which signals their robustness. The eight priorities were simulated subject to a set of a priori constraints on the simplex. The restrictions set $\Xi$ adopted in the simulations may be schematically written as an intersection of four restrictions $\Xi_{1}:=\cap_{h \in\{1,2,3,4\}} \Xi_{h}$, where $\Xi_{1}=\left\{v_{[R C]}>v_{[P s]}, v_{[R d]}, v_{[S h]}, v_{[H C]}, v_{[S c]}, v_{[C u]}\right\}, \Xi_{2}=\left\{v_{[\mathrm{Un}]}>v_{[\mathrm{Rd}]}, v_{[\mathrm{Sh}]}, v_{[\mathrm{HC}]}, v_{[\mathrm{Sc}]}, v_{[\mathrm{Cu}]}\right\}$, $\Xi_{3}=\left\{v_{[\mathrm{Rd}]}, v_{[\mathrm{Sh}]}, v_{[\mathrm{HC}]}, v_{[\mathrm{Sc}]}>v_{[\mathrm{Cu}]}\right\}$, and $\Xi_{4}=\left\{v_{[\mathrm{Ps}]}, v_{[\mathrm{Un}]}, v_{[\mathrm{RC}]}, v_{[\mathrm{Rd}]}, v_{[\mathrm{Sh}]}, v_{[\mathrm{HC}]}\right.$, $\left.v_{[\mathrm{Sc}]}, v_{[\mathrm{Cu}]}>0.025\right\}$. Out of these, $\Xi_{1}$ stipulates the greatest priority to [RC] except that its comparative status to [Un] is not specified. Similarly, $\Xi_{2}$ assigns to [Un] a greater priority than to the 5 attributes describing the general civil infrastructure. In effect, $\Xi_{3}$ says that the cultural attribute $[\mathrm{Cu}]$ is least important. Finally, $\Xi_{4}$ warrants each priority is 0.025 at least and that trivially small priorities are not considered in the MCDA evaluation. All in all, these restrictions imply that a typical Slovak resident is extremely sensitive to a Romany population living in a close or distant neighborhood and unfavourable employment prospects, and that he prioritizes cultural amenities at the last place. This is in line with a survey conducted by the Institute for Public Affairs (Velšic, 2017) that reveals a relatively strong intolerance of national, religious or sexual minorities. As many as $80 \%$ of young people (aged 18-39) are resentful about the idea that they should live close to a Roma family, and $54 \%$ have a problem with immigrants from economically weaker families. The survey was repeated after two years (Bútorová and Gyárfašová 2019), this time on the age group 
Table 5 Statistics of the priorities assigned to the viability attributes during the simulations

\begin{tabular}{lllllllll}
\hline Descriptive & {$[\mathrm{Ps}]$} & {$[\mathrm{Un}]$} & {$[\mathrm{RC}]$} & {$[\mathrm{Rd}]$} & {$[\mathrm{Sh}]$} & {$[\mathrm{HC}]$} & {$[\mathrm{Sc}]$} & {$[\mathrm{Cu}]$} \\
\hline Mean & 0.093 & 0.239 & 0.251 & 0.094 & 0.094 & 0.094 & 0.094 & 0.040 \\
Standard deviation & 0.052 & 0.079 & 0.078 & 0.040 & 0.040 & 0.039 & 0.039 & 0.013 \\
Median & 0.083 & 0.223 & 0.235 & 0.089 & 0.089 & 0.089 & 0.089 & 0.036 \\
Minimum & 0.025 & 0.052 & 0.061 & 0.025 & 0.025 & 0.025 & 0.025 & 0.025 \\
Maximum & 0.366 & 0.699 & 0.692 & 0.263 & 0.265 & 0.259 & 0.259 & 0.120 \\
\hline
\end{tabular}

Table 6 Statistics and correlations of the multiattribute utilities calculated for municipalities

\begin{tabular}{llll}
\hline Descriptive & Additive & CD & Overall \\
\hline Mean & 0.495 & 0.384 & 0.440 \\
Standard deviation & 0.145 & 0.178 & 0.159 \\
Median & 0.485 & 0.381 & 0.434 \\
Minimum & 0.131 & 0.000 & 0.065 \\
Maximum & 0.817 & 0.787 & 0.802 \\
Correlation coefficients & & & \\
Additive & 1.000 & 0.935 & 0.980 \\
CD & 0.935 & 1.000 & 0.972 \\
Overall & 0.980 & 0.972 & 1.000 \\
\hline
\end{tabular}

of $15-19$; and the results still show the unwillingness to live next to a Roma family ( $61 \%$ of the respondents). This might be owing to the way of life that most of the Roma population lead: many of their settlements lack formal infrastructure, access to drinking water, and proper sewage systems (Klimovský et al. 2016) which leads to more health problems (Kósa et al. 2007) and the majority feels threatened by disease on top of the higher crime rate. An outbreak of COVID-19 virus among a few Roma settlements in the crisis period of spring 2020 also added to the worries about these communities.

Table 5 summarizes basic properties of the resulting priorities computed for the 100,000 simulation. A quick glance confirms that the simulated priorities are consistent with the set of constraints $\Xi$. The attributes [Un] and [RC], preordained by the constraints in $\Xi$ the most important status, explain about one half of the utility of living in a municipality.

The outcome of the MCDA evaluations were multi-attribute utilities, or scores, in the interval [0,1] capturing for each of the 115 municipalities over 1,000 inhabitants in the Banská Bystrica region its viability for life. A detailed report of the results is postponed to Appendix C. Meanwhile, Table 6 presents statistical descriptives of not only the overall scores, but also of their additive and Cobb-Douglas components (the arithmetic and geometric means in the right-hand part of expression (4) without the equal 0.50 weights, respectively). Cobb-Douglas components of the scores are 


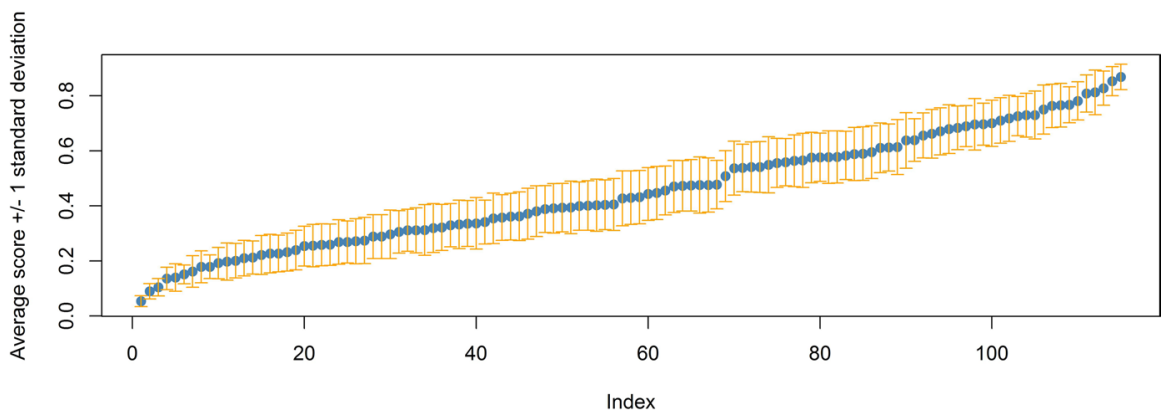

Fig. 1 Ascendingly ordered multi-attribute utilities with uncertainty error bars

sterner (lower) than additive components, which is understandable for any zero utility amongst those to be averaged entails a zero score. Nevertheless, the high positive correlation coefficients prove that there is little discord between the additive and Cobb-Douglas components, but also that their hybrid representation in the form of overall scores is closer to both of them. The ranking is equitable or mild in the sense that the cut-off between the better and worse halves of the municipalities is around the midst of the range over which the scores spread. This even distribution of overall scores is also discernible in the index plot of Fig. 1 that displays the scores sorted in ascending order with error bars \pm one standard deviation. The scores arose by averaging over 100,000 simulations, and the standard deviations were computed from this batch of simulation runs. The uncertainty associated with individual scores is alike except the few worst and best municipalities.

Appendix $\mathrm{C}$ organizes some basal information for the 11 district towns in the Banská Bystrica region and a few municipalities that came out as best or worst in the MCDA assessment (in order to economize on space the report is limited to a sample of municipalities that is representative in terms of the results). The overall score represents the ultimate multi-attribute utility $V$ given by Eq. (4) and the preceding columns declare the values of input attributes $A_{1}, \ldots, A_{8}$ entering the calculation. Scores are presented with corresponding standard deviations that are instrumental in gauging their uncertainty stemming from the simulations. The table in Appendix $\mathrm{C}$ displays this information for the best 14 municipalities (ranks 1-14) as well as for the worst 14 (ranks 101-105). Intriguingly, the three top municipalities are in fact villages in the vicinity of Banská Bystrica, whereas Banská Bystrica and Zvolen themselves, district towns, are positioned in the fourth and tenth place, respectively. Moreover, the best 14 municipalities are all in the commuter zone of BB/ZV. In contrast, the worst 14 municipalities are located far from this zone and are, as a matter of fact, villages in less prosperous districts. These least viable municipalities are typically characterized by high Romany concentration, worse access to the state-wide road network, and poor civil infrastructure. Especially, the worst ranked municipality, Rimavská Seč, is the worst municipality in terms of job opportunities and concentration of the Romany population (zero attributes [Un] and [RC]).

It is interesting in this respect to note that Slovak sociological geography traditionally operates with the municipal typology developed by Gajdoš et al. (2009) that 
classifies municipalities into 9 ordinal categories described in Sect. 2. It must be said that a municipality with a numerous marginalized Romany community displays typically the definitional characteristics of category 8 of "villages with high natality and populated predominantly by inhabitants of pre-productive age". The last column of the table in Appendix $\mathrm{C}$ reports this classification. Although this typology is heavily used and respected (Andráško and Ira, 2010; Huba et al. 2010; Bleha, 2011; Jaszczak et al. 2018; Klobučník et al. 2018), it produces classifications that are not very compliant with the present viability assessment of municipalities. The optimal scaling procedure of Young (1981) employed to transform the ordinal scale of the categories introduced by Gajdoš et al. (2009) into continuous measurements identified that the correlation may vary between 0.229 and -0.783 . In addition, the traditional Spearman correlation coefficient between the ranks induced by the present MCDA assessment and the categories of Gajdoš et al. (2009) was -0.613. Both these results point to the inadequacy of the typology of Gajdoš et al. (2009). One reason may be that it is simply outdated or that it considers economic activities or birth rates dominant in municipalities as an aspect for classification, which does not actually explain whether a municipality offers satisfactory conditions for life. Another factor to consider is that even at first glance some municipalities are assigned under the typology of Gajdoš et al. (2009) into unbecoming categories. For instance, some district towns in the Banská Bystrica region that are classified by Gajdoš et al. (2009) into category 1, as seen in Appendix C, display conclusively more rural signs than features of an urban centre. A few cross-examples can be produced for villages as well. The monotonically ascending pattern of scores revealed in Fig. 1 indicates sort of a continuous ranking, without severe bumps. Indeed, even an attempt to employ the k-means algorithm to identify compact clusters did not yield satisfactory results. For instance, the gap statistic of Tibshirani et al. (2001) recommended the existence of one cluster. It is still possible to slice the municipalities into contiguous classes to set up an ordinal classification, but the cut-offs would have to be determined to a great extent on judgement. Nonetheless, the present MCDA assessment gives a unique perspective into the viability of municipalities well above simple size measures. There is no compelling relationship of the overall scores to municipal population size or density (correlation coefficients both around 0.20 ).

\section{Discussion and concluding notes}

This paper challenges the prevailing narrative that small and medium towns are becoming unattractive for life. With a focus on Slovakia, this stylized statement is inspected against multi-attribute scores constructed by exploiting features of DEA and MCDA modelling as comprehensive descriptors of viability of towns for life. Terminologically, viability is construed here as universal desirability to live in a particular municipality and not elsewhere, and is composed of eight factors that aspire to capture niceties or adversities of municipal life. The case study concerns the municipalities counting over 1000 inhabitants and located in the Banská Bystrica region of Slovakia, and demonstrates that small localities are comparable in viability for life to larger commuter centres and can even surpass them. That said, the key factor is 
obviously the distance from a commuter centre. Amongst the ten most perspective localities for life, aside from the commuter epicentres, Banská Bystrica and Zvolen, there are 4 municipalities in the close vicinity of Banská Bystrica and four in the nearness of Zvolen. Furthermore, Banská Bystrica itself occupies the fourth place and Zvolen the tenth. All these municipalities are peripheral with prevalent urban or urban-like characteristics; and these run counter to those that are particular for municipalities positioned at the bottom of the ranking. These localities are distant from the $\mathrm{BB} / \mathrm{ZV}$ commuter zone and have definite rural features. They are characterized typically by lessened or no availability of health care, schooling and culture, albeit the joint weight of these attributes in the assessment is about one fourth (on average, a weight of 0.228 in total). Still, the worst assessment holds for municipalities that are deemed generally economically unattractive (with prosperous agricultural, forestry and mining activities in the past, but currently in disarray) and are with poor civic availability (health care, schooling, culture and shopping), which triggers or deepens a vicious circle. In the conditions of Slovakia, municipalities (all cities, towns and villages) are by law accountable among other things also for the provision of health care, education, culture, physical culture and sports. The analysis has confirmed the importance of these factors for the viability of municipalities. It transpires, however, that most municipalities are not able to meet the demands for nursery and primary schools, health care and sports facilities, which is due to their limited resources. The public administration reforms passed many obligations and competences onto municipalities, but the fiscal decentralization did not secure enough finance for fulfilling these obligations at the local government level in many CEE countries (Plaček et al. 2020; Bird and Wallich, 1994). Changing the urban hierarchy and creating network based models might ease the provision of civic availability (e.g. Neal, 2011; Hall et al. 2001). Nonetheless, these models count with complementarity of municipalities which is not a desired effect when promoting viability of a particular town. Strategic planning with a focus on other criteria (mostly demographics) and innovative methods such as temporary use in urban regeneration (Patti and Polyák, 2017) might help towns to achieve better availability of civic facilities.

Although the interest lies solely in a category called viability, it touches three other areas that merit some discussion. First, to some extent it builds on the traditional urban-rural life dichotomy in terms of life satisfaction. Indeed, places whose inhabitants have grounds to display greater happiness are preferable for life. The traditional premise is that dwellers in urban areas feel more satisfaction since economic growth takes place chiefly in urban areas. Unsurprisingly, this story has much in common with the prevailing narrative being studied. Nonetheless, the current stance of development economics is that urban and rural life satisfaction tends to converge and differences in urban and rural areas that matter for subjective well-being begin to evaporate (Easterlin et al. 2011; Requena, 2016). The dilution of differences in urban-rural life satisfaction is not only owing to economic development, but is also a by-product of population ageing since older population can choose a place of residence irrespective of their previous place of work and moves to rural residences (Easterlin et al. 2011). In addition, urban and rural areas are layered in terms of distance from large central cities through small-town peripheries to remote rural locations. Berry and Okulicz-Kozaryn (2011) report that the highest levels of satisfaction in the USA are found for small towns and 
close areas in the commuter periphery of a city. Their finding is consistent with the measurement in this paper as the municipalities located in the heart of the BB/ZV commuter zone lead the ranking partly presented in Appendix C. All these localities are well within a 30-min radius away from Banská Bystrica and/or Zvolen, and can enjoy the advantages that either city offers. Of course, subjective well-being and viability are different categories. For example, Gilbert et al. (2016) observed that inhabitants in Scottish remote rural localities (with 3000 inhabitants at most with more than a 30-min drive time to a nearby town) are more satisfied with their life than those in other parts of the country, which they explained by stronger family ties and social interactions, and by better opportunities for sports activities. Unlike Gilbert et al. (2016), the present paper does not go beyond objective attributes that contribute to a municipality's potential for life and cannot handle psychological assessments. Furthermore, the comparative excess of life satisfaction of urban over rural residents does not exert universal validity since, e.g., Valente and Berry (2016) found no difference in urban-rural differences.

The second point is perhaps more pertinent, and it is quality of life. Measuring viability for life crosses with measuring quality of life, which is a more objective criterion than subjective perception of well-being. Quality of life (QOL) is a multi-faceted integrated concept for evaluating the living standards of people by accounting for economic, social, cultural, political, ecological and other aspects (Ma et al. 2020, p. 10) that has both an objective and a subjective component (Marans, 2015, p. 48; Ward and Brown, 2009). In consequence, QOL indicators may be in spirit similar to the present multi-attribute scores, but are constructed as a blend of objective criteria (that represent, e.g., economic activity, infrastructure, sustainability, ecology, availability of different kinds of amenities, incidence of unfavourable phenomena) and subjective metrics (that represent perceptions, behavioural patterns or personal preferences). In contrast, viability is here introduced as a similar concept that integrates multiple dimensions in order to evaluate whether a particular place possesses sufficient material conditions and has a favourable socio-demographic environment that make it preferable for living. Unsurprisingly, the QOL topic is frequently handled as an assessment of urban-rural disparity or integration (e.g., Liu and Zhang, 2018; Li et al. 2019; Sumity and Raminder, 2018). As a matter of fact, viability, as is understood here, corresponds to the objective axis of QOL and overlooks subjective metrics.

Finally, there is another very similar concept, that of urban vitality that is studied typically for urban areas and viewed as an engine of urban, mostly economic, development (Lan et al. 2020; Jin et al. 2017). Several angles can be accommodated such as a cultural and creative outlook (Montalto et al. 2019), input of human capital (Yang and Pan, 2020), but the ultimate goal is to ascertain the position of an urban centre (typically a city) between two poles: a prosperous pulsing cell of urban life versus a dying shrinking area. The latter is called aptly by Jin et al. (2017) as a ghost city. Urban vitality is measured by indicators that capture the level of economic activity or potential to undertake in different activities which divorces this concept from the notion of viability as it does not provide the answer as to whether a place would be chosen as a residence for life. Indicators measuring human capital, talent and education, innovation and research, government and regulations, tolerance and diversity, creative output, technology and entrepreneurship are fairly common (Montatlo et al. 2019). 
The model for measuring the viability of localities for life currently consists of eight attributes tailored to the conditions of a post-socialist country abounding with economic and social problems sui generis. These include: population structure [Ps], unemployment [Un], Romany concentration [RC], road accessibility [Rd], shopping opportunities [Sh], infrastructure of health-care, school and cultural facilities [HC, Sc, $\mathrm{Cu}$. The measurement of viability might be extended by allowing natural factors or amenities (Sánchez-Zamora et al. 2014; Winters and Li, 2017), sights and landmarks, tourist attractiveness, municipal governance (Montalto et al. 2019), or quality of the environment (Silva, 2015). A unique ingredient of the model is that it directly incorporates the adverse effect of a (dense) Romany population which is perceived by many Slovaks as detrimental. The consideration of this factor is similar to considering ethnic minorities such as negro or Hispanic inhabitants for the USA (e.g. Valente and Berry, 2016; Thiede et al. 2018; Niemesh and Shester 2020), but in Slovak conditions it is frequently imputed a flavour of racism and disallowed as incorrect. To some extent, the $[\mathrm{RC}]$ factor might be replaced by election preferences as the attitudes to minorities such as the Roma population are significantly influenced by the inclination towards political parties (Velšic, 2017). Although lenient restrictions were imposed by means of ordering the attributes in terms of relevance, the $[\mathrm{RC}]$ factor received the highest weight in the assessment (on average, 0.251). In spite of the said importance of [RC], the municipalities under study suffer chiefly for large disparities in shopping opportunities [Sh] and grave discrepancies in availability of health-care, school and cultural facilities $[\mathrm{HC}, \mathrm{Sc}, \mathrm{Cu}]$. Shops and diverse infrastructure are spatially concentrated in larger district towns, especially in Banská Bystrica and Zvolen, and from many localities across the territory are by all standards distant. Most localities that fare worst are also reachable with difficulties from an expressway or are surrounded by an unsatisfactory road network. In view of the geographical location, these municipalities would obviously benefit from the speedy completion of the expressways that are slated to be built. Highways are the best method for overcoming the tyranny of distance, a term coined by Blainey (1966), which is measured in time, distance and safety.

Despite the fact that the analysis was applied to one region of Slovakia and only to municipalities over 1,000 inhabitants, the model is transferable to other applications and is also adjustable. When necessary, different partial indicators are aggregated into attributes in a model-based fashion without the analyst's input using a common-set-of-weights DEA procedure without explicit inputs (CSW DEA-WEI). Different attributes are weighted and aggregated in a standard way, but the weights are specified with a minimum of information, perhaps allowing only some ordering preferences between some or all attributes. By Monte Carlo simulations, the space of all weights that uniformly satisfy the restrictions is searched over with full consideration given to the uncertainty underpinning the assessment. This approach is novel in comparison to the practise of constructing QOL and life satisfaction assessments or to the methodology of deriving an urban-rural typology. Usually indices are set-up by aggregating at several levels using fixed deterministic weights (e.g., Ma et al. 2020; Montalto et al. 2019) or based on a DEA model without a common set of weights (e.g., Sánchez-Zamora et al. 2014; Morais and Camanho, 2011). 


\section{Appendix A}

\section{See Table 7}

Table 7 Factors employed in assessments of life attractiveness in municipalities

\begin{tabular}{|c|c|}
\hline Study & Description and additional characterization \\
\hline Alston (2002) & $\begin{array}{l}\text { Population/demographics, employment opportunities, access to educa- } \\
\text { tion, social capital }\end{array}$ \\
\hline Buček et al. (2014) & Economic structure, population size \\
\hline Chambers (1994) & Tangible productive factors, social capital \\
\hline Easterlin et al. (2011) & Income, education, occupational structure, pollution, congestion \\
\hline Gajdoš et al. (2009) & $\begin{array}{l}\text { Municipality size, unemployment, number of job seekers, occupancy } \\
\text { rates in industry, agriculture and services, education, number of flats, } \\
\text { number of commuting citizens, birth-rate, migration of citizens, age } \\
\text { structure }\end{array}$ \\
\hline Goudy (1977) & $\begin{array}{l}\text { Age structure, public transport, health care access and other amenities, } \\
\text { community satisfaction }\end{array}$ \\
\hline Klimovský et al. (2016) & Romany factor \\
\hline Libang et al. (2020) & $\begin{array}{l}\text { Spatial distance, economic development, social conditions, living } \\
\text { environment }\end{array}$ \\
\hline Marans (2015) & $\begin{array}{l}\text { Objective indicators (employment, education, per capita income, } \\
\text { crime statistics, domestic violence, death rate, air quality, residential } \\
\text { density, distance to transit stop, availability of grocery shops, vehicle } \\
\text { miles travelled), subjective indicators (perception of crime, of school } \\
\text { and health care quality, desire to move, satisfaction with housing and } \\
\text { neighbourhood, overall well-being) }\end{array}$ \\
\hline Montalto et al. (2019) & Sights and landmarks, tourist attractiveness, municipal governance \\
\hline Sánchez-Zamora et al. (2014) & $\begin{array}{l}\text { economic diversification (rural tourism), agriculture (young farmers, } \\
\text { organic production), access to services (infrastructures and facilities), } \\
\text { demographics (foreign population), natural resources and governance } \\
\text { (rural development funding management) }\end{array}$ \\
\hline Silva (2015) & $\begin{array}{l}\text { Air pollution metrics (concentration of carbon monoxide, nitrogen } \\
\text { dioxide, particulate matter, ozone), healthy noise metric (noise } \\
\text { annoyance indicator) }\end{array}$ \\
\hline Toma and Mathijs (2007) & $\begin{array}{l}\text { Age, education, access to agricultural and environmental information, } \\
\text { number of children, land ownership }\end{array}$ \\
\hline Vollet (2002) & Biodiversity, demand for space, landscape, leisure \\
\hline Yin et al. (2019) & $\begin{array}{l}\text { Living cost, traffic, air pollution, demand for industry upgrading, } \\
\text { resources, social trust, human capital }\end{array}$ \\
\hline
\end{tabular}

There is some simplification for the studies enumerated in the table were concerned with different aspects of living and its attractiveness. Some of them aspired to give a thorough assessment of the schism of urban and rural life (e.g. Easterlin et al. 2011; Alston, 2002; Goudy, 1977), others were interested in developing environmental indicators (e.g. Silva, 2015) or hoped to include all possible aspects and make a general assessment (e.g. Gajdoš et al. 2009; Marans, 2015) 


\section{Appendix B}

\section{Methodological details on the construction of evaluations}

GPS coordinates for Slovak municipalities to construct inter-municipal distances and spatial weights were sourced from Wikipedia's Geohack database (see https:// www.mediawiki.org/wiki/GeoHack).

[PS] Population structure Economic dependency ratio is defined as the ratio of \# persons aged 14 years at most and persons aged 65 years at least to \# persons aged 15 to 64 years. This is a static indicator of population structure whose small value suggests that there are too many people in the pre-productive and post-productive age relative to economically active population. To turn it to maximization for municipality viability, it was inverted and its 2008 reciprocal values were employed. The other indicator, the rate of change in \# persons aged 40 years at most to \# persons aged more than 40 years, is a dynamic indicator of population structure. A value greater than 1 over a decade (or any longer period) indicates a tendency of the population to grow youthful and "rejuvenate". This indicator was employed without transformation, mapping the change between 2008 and 2018. The weights of the static and dynamic indicator in the composite index were determined by CSS WEI-DEA. No spatial averaging was employed for population structure is a factor of a specific place without discernible spatial spill-over effects.

[Un] Unemployment Since sufficiently detailed statistics at a municipal level are not available, registered job seekers are used as a proxy for unemployed persons. The transformation of this single metric evaluated for 2008 to the interval $[0,1]$ recognized that smaller values are preferable as they indicate that local market conditions are conducive to job security. Given the ever-present labour mobility (especially of labour force from smaller to larger municipalities), this metric was spatially averaged.

[RC] Romany concentration The percentage concentration of the Romany population in municipalities estimated as of December 2010 was available from Matlovičová et al. (2012) in the form of unevenly spaced interval classes $0 \%$, $0.1-1 \%, 1.1-5 \%, 5.1-10 \%, 10.1-20 \%$, and so forth by 10 percentage points. Instead of these ordinal classes, their midpoints were used and transformed to the interval $[0,1]$ with full regard given to the fact that smaller values are more acceptable for socially integrated inhabitants. The normalized values were spatially averaged to account for the fact that Slovaks are sensitive to locally concentrated clusters of the Romany population. Unfortunately, data on the Romany concentration could not be sourced from the Atlas of Roma communities in Slovakia 2019 provided by the Ministry of the Interior of the Slovak Republic (https://www.minv.sk/?atlas-romskych-komunit-2019) for too many municipalities reviewed in the present analysis are not covered in the publication.

[Rd] Roadways With respect to the spatial coverage of road networks in 2018, three distances were integrated into a single composite index by CSS DEA-WEI, i.e., the distance of a municipality to a 4-lane expressway, and the parts of this 
distance that must be driven on non-first-class and treacherous roads. Nonetheless, distances to a 4-lane expressway smaller than $5 \mathrm{~km}$ were treated as zeros since the expressway was in such cases within arm's reach. Values for each metric were turned into maximization by subtracting them from the maximum observed on that metric. This calculation was performed separately for each metric. Spatial averaging in this case would not make sense as distances of individual municipalities from the state's main transportation network do not impact one another.

[Sh] Shopping In the Banská Bystrica region, only district towns offer opportunities to do the shopping in malls or have large discount retailers residing in their territory. Therefore, these two metrics representing the shopping attribute were expressed relative to the travelling time in minutes to reach the district town plus a surcharge of $10 \mathrm{~min}$ for travelling across the district town. Accordingly, these metrics were defined as \# of indoor and outdoor shopping malls or large discount retailers (Tesco, Lidl, Kaufland, Terno, Billa) divided by the travelling time to the district increased by $10 \mathrm{~min}$. In consequence, district towns were by default penalized by a non-zero distance of $10 \mathrm{~min}$, which is a reasonable (average) time to get to a nearby supermarket or mall in typical Slovak town. In order to account for cross-districtual shopping, which is a fairly frequent practice, the resulting composite indices resulting from CSS DEA-WEI were spatially averaged.

[HC] Health care The counts of different health care facilities in municipalities were integrated via CSS DEA-WEI into a composite index and spatially averaged in order to account for reachability and substitutability of health care services between different municipalities. Admittedly, this procedure is sort of rough since substitutability applies differently across the range of health-care facilities. Whereas pharmacies and medical aid supply points are nearly perfectly substitutable, substitutability of hospitals or specialized outpatient facilities is marginal at best.

[Sc] Schools Similarly as with [HC].

[Cu] Culture Similarly as with [HC].

\section{Appendix C}

See Table 8. 


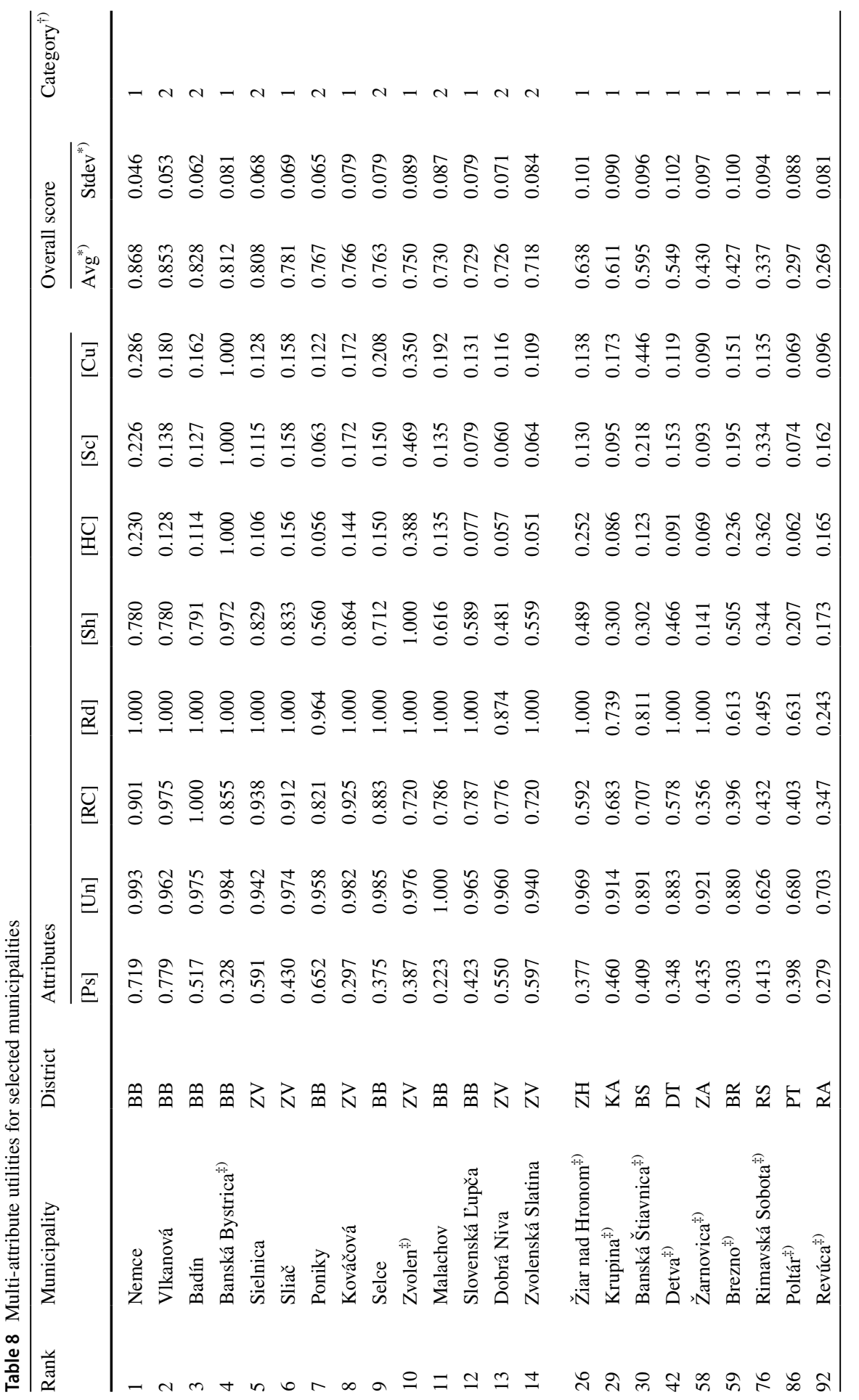




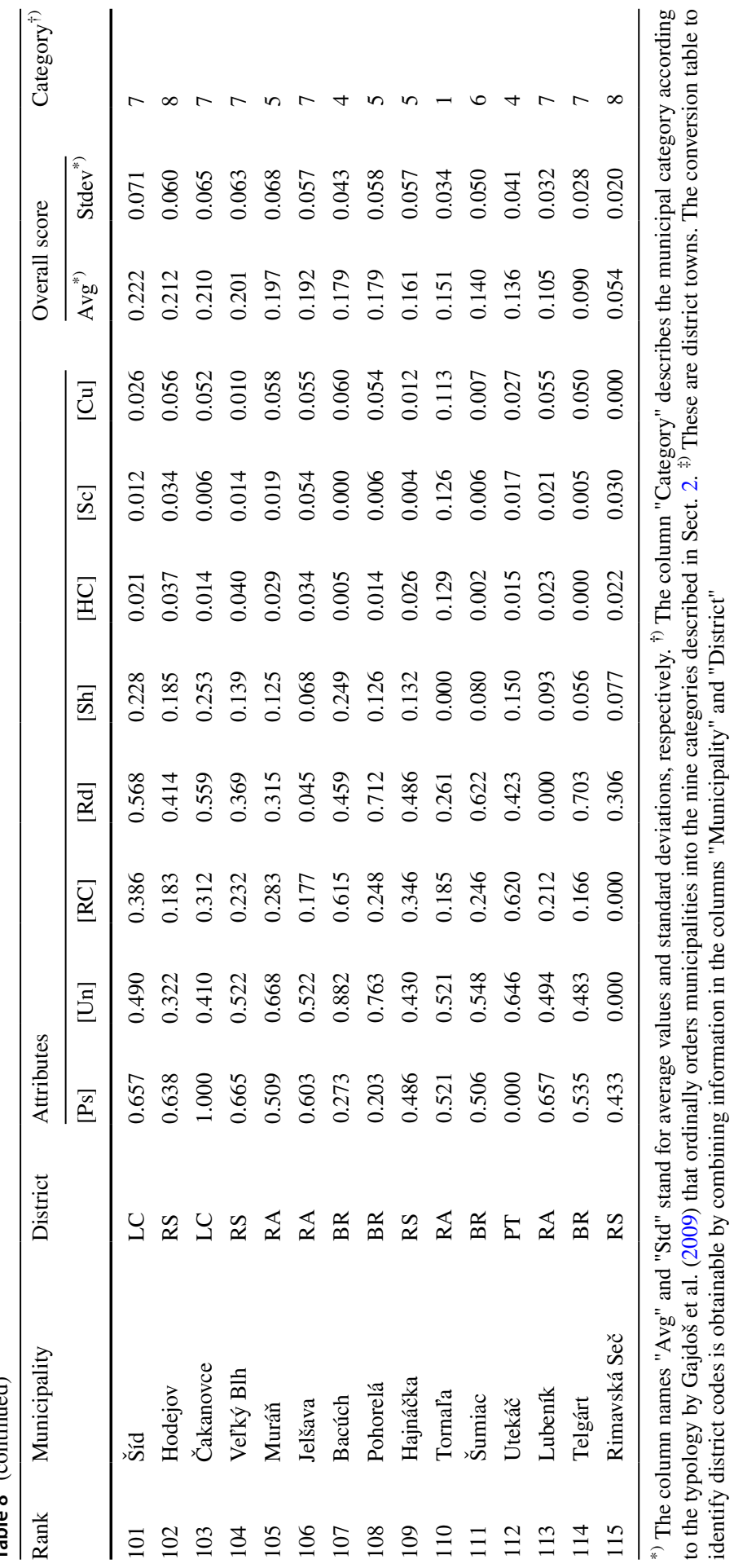


Funding This research is supported by VEGA [grant number 1/0786/18].

\section{Declarations}

Conflict of interest The author declared that there is no conflict of interests.

\section{References}

Alston M (2002) Inland rural towns: are they sustainable? in keynote address to the ABARE Outlook Conference, Canberra, March (pp. 5-7)

Andráško I, Ira V (2010) Analysis of social infrastructure in the districts Levice, Rimavská Sobota, Bardejov in the context of municipal size criteria and standards of minimum facilities availability. Geographia 27:101-133

Anselin L (1988) Spatial econometrics: methods and models. Kluwer Academic Publishers, Dortrecht Arbia G (2014) A primer for spatial econometrics. Palgrave Macmillan, Basingstoke

Bartošová J, Želinský T (2013) The extent of poverty in the Czech and Slovak Republics 15 years after the split. Post-Communist Econ 25(1):119-131

Berry BJL, Okulicz-Kozaryn A (2011) An urban-rural happiness gradient. Urban Geogr 32(6):871-883

Bird RM, Wallich C (1994) Local finance and economic reform in Eastern Europe. Eviron Plann C Gov Policy 12(3):263-276

Blainey G (1966) The tyranny of distance: how distance shaped Australia's history. Sun Books, Melbourne

Bleha B (2011) Local demographic development in Slovakia: Perception, social implications and interdisciplinary prospects. Sociológia 43(4):362-390

Buček J et al. (2014) Definition of towns and municipalities in Slovakia, including evaluation of functional types of settlements, based on population density, using raster technology. Commenius University in Bratislava, Bratislava

Bútorová Z, Gyárfášová O (2019) Civic coexistence in the eyes of teenagers: a sociological study., Institute for Public Affairs, Bratislava. Available online at http://www.ivo.sk/buxus/docs//publikacie/ subory/Obcianske_spolunazivanie_ocami_tinedzerov_2019.pdf

Carr P, Kefalas M (2009) Hollowing out the middle: the rural brain drain and what it means for America. Beacon Press, Boston

Chambers R (1994) Participatory rural appraisal (PRA): challenges, potentials and paradigm. World Dev 22(10):1437-1454

Cherchye L, Knox Lovell CA, Moesen W, van Puyenbroeck T (2007a) One market, one number? a composite indicator assessment of EU internal market dynamics. Eur Econ Rev 51(3):749-779

Cherchye L, Moesen W, Rogge N, van Puyenbroeck T (2007b) An introduction to 'benefit of the doubt' composite indicators. Soc Indic Res 82(1):111-145

Cherchye L, Moesen W, Rogge N, van Puyenbroeck T, Saisana M, Saltelli A, Liska R, Tarantola S (2008) Creating composite indicators with DEA and robustness analysis: the case of the technology achievement index. J Oper Res Soc 59(2):239-251

Cylus J, Papanicolas I, Smith PC (2017) Using data envelopment analysis to address the challenges of comparing health system efficiency. Global Pol 8(2):60-68

Demographia (2020) Demographia world urban areas (built-up urban areas or urban agglomerations), 16th annual edition. Available online at http://demographia.com/db-worldua.pdf

Despotis DK (2005a) A reassessment of the human development index via data envelopment analysis. J Oper Res Soc 56(8):969-980

Despotis DK (2005b) Measuring human development via data envelopment analysis: the case of Asia and the Pacific. Omega 33:385-390

Dietrich H, Möller J (2016) Youth unemployment in Europe-business cycle and institutional effects. IEEP 13(1):5-25

Doumpos M, Zopounidis C (2013) Efficiency and performance evaluation of European banks. In: Pasiouras, F., Editor, 2013. Efficiency and productivity growth: Modelling in the financial services industry, Wiley, New York. 
Easterlin RA, Angelescu L, Zweig JS (2011) The impact of modern economic growth on urban-rural differences in subjective well-being. World Dev 39(12):2187-2198

Eurofound (2019) Is rural Europe being left behind? European quality of life survey. Publications Office of the European Union, Luxembourg. Available online at https://op.europa.eu/en/publication-detail/-/ publication/

Federal institute for research on building, urban affairs, and spatial development, 2013. Growing and shrinking regions in Europe. Analytical report. Available online at https://www.bbr.bund.de/BBSR/ EN/SpatialDevelopment/SpatialDevelopmentEurope/AnalysesSpatialDevelopment/Projects/growi ng_shrinking/growing_shrinking.html

Gaaloul H, Khalfallah S (2014) Application of the 'benefit-of-the-doubt' approach for the construction of a digital access indicator: a revaluation of the 'Digital Access Index.' Soc Indic Res 118(1):45-56

Gaile GL (1992) Improving rural-urban linkages through small town market-based development. Third World Plan Review 14(2):131

Gajdoš P, Moravanská K, Faltan L' (2009) Specifics of the municipal development in Slovakia-typological analysis. Sociological Institute of the Slovak Academy of Sciences, Bratislava

Gallie D, Kostova D, Kuchař P (2001) Social consequences of unemployment: an East-West comparison. J Eur Soc Policy 11(1):39-54

Giannone E (2017) Skill-biased technical change and regional convergence. In 2017 Meeting Papers (No. 190). Society for Economic Dynamics

Gilbert A, Colley K, Roberts D (2016) Are rural residents happier? a quantitative analysis of subjective wellbeing in Scotland. J Rural Stud 44:37-45

Goliaš P (2016) Solutions to high unemployment rate-case of Slovakia., Institute for Economic and Social Reforms, Bratislava. Available online at http://www.ineko.sk/clanky/webinar-solutions-tohigh-unemployment-rate

Goliaš P (2017) Regional differences in the Slovak Republic_an overview of important statistics, Institute for Economic and Social Reforms, Bratislava. Available online at http://www.ineko.sk/clanky/ ako-znizovat-regionalne-rozdiely-na-slovensku.

Goudy WJ (1977) Evaluations of local attributes and community satisfaction in small towns. Rural Sociol 42(3):371-381

Grupp H, Schubert T (2010) Review and new evidence on composite innovation indicators for evaluating national performance. Res Policy 39(1):67-78

Halás M, Klapka P, Bačík V, Klobučník M (2017) The spatial equity principle in the administrative division of the Central European countries. PLoS ONE 12(11):e0187406

Hall P, Marshall S, Lowe M (2001) The changing urban hierarchy in England and Wales, 1913-1998. Reg Stud 35(9):775-807

Hatefi SM, Torabi SA (2010) A common weight MCDA-DEA approach to construct composite indicators. Ecol Econ 70:114-120

Hovanov N, Yudaeva M, Hovanov K (2009) Multicriteria estimation of probabilities on basis of expert non-numeric, non-exact and non-complete knowledge. Eur J Oper Res 195(3):857-863

Howell AM (2013) Raised up down yonder: growing up black in rural Alabama. University of Mississippi Press, Mississippi

Huba M, Ira V, Chrenka B (2010) Environmental situation of urban and rural Slovak towns by selected indicators. Geographia 27:57-79

Ishizaka A, Labib A (2011) Review of the main developments in the analytic hierarchy process. Expert Syst Appl 38(11):14336-14345

Jaszczak A, Kristiánova K, Vaznoniene G, Žukovskis J (2018) Phenomenon of abandoned villages and its impact on transformation of rural landscapes. Manag Theory Stud Rural Business Infrastruct Develop 40(4):467-480

Jin X, Long Y, Sun W, Lu Y, Yang X (2017) Evaluating cities' vitality and identifying ghost cities in China with emerging geographical data. Cities 63:98-109

Kenyon P, Black A (2001) Small town renewal: overview and case studies. Rural Industries Research and Development Corporation, Canberra

Klimovský D, Mejere O, Mikolaityte J, Pinteric U, Saparniene D (2014) Inter-municipal cooperation in Lithuania and Slovakia: does size structure matter? Lex Localis 12(3):643-658

Klimovský D, Želinský T, Matlovičová K, Mušinka A (2016) Roma settlements and poverty in Slovakia: different policy approaches of the state, local governments, and NGOs. Anthropological Notebooks 22(1):23-42 
Klobučník M, Bačík V, Matiašová M, Fila R (2018) Negative aspects of municipal amalgamation within the municipal reform-the perspective on the example of the Slovak Republic. Sociologia 50(4):448-481

Kósa Z, Széles G, Kardos L, Kósa K, Németh R, Országh S, Vokó Z (2007) A comparative health survey of the inhabitants of Roma settlements in Hungary. Am J Public Health 97(5):853-859

Krugman P (2017) The gambler's ruin of small cities, The New York Times, Dec 30, 2017. Available online at https://www.nytimes.com/2017/12/30/opinion/the-gamblers-ruin-of-small-cities-wonki sh.html

Lahdelma R, Hokkanen J, Salminen P (1998) SMAA—stochastic multiobjective acceptability analysis. Eur J Oper Res 106(1):137-143

Lan F, Gong X, Da H, Wen H (2020) How do population inflow and social infrastructure affect urban vitality? Evidence from 35 large- and medium-sized cities in China. Cities 100, 102454

Langhans SD, Reichert P, Schuwirth N (2014) The method matters: a guide for indicator aggregation in ecological assessments. Ecol Ind 45:494-507

Li YH, Westlund H, Liu YS (2019) Why some rural areas decline while some others not: an overview of rural evolution in the world. J Rural Stud 68:135-143

Libang M, Liu S, Fang F, Che X, Chen M (2020) Evaluation of urban-rural difference and integration based on quality of life. Sustain Cities Soc, 54, 101877

Liu FHF, Peng HH (2008) Ranking of units on the DEA frontier with common weights. Comput Oper Res 35(5):1624-1637

Liu CF, Zhang ZY (2018) From town-country integration to urban-rural integration: New thinking on the relationship between urban and rural areas. Scientia Geographica Sinica 38(10):1624-1633

Liu WB, Zhang DQ, Meng W, Li XX, Xu F (2011) A study of DEA models without explicit inputs. Omega 39:472-480

Lubyová M, van Ours JC (1999) Unemployment durations of job losers in a labour market in transition. Econ Transit 7(3):665-686

Ma L, Liu S, Fang F, Chen X, Chen M (2020) Evaluation of urban-rural difference and integration based on quality of life. Sustain Cities Soc, 54, 101877

Marans RW (2015) Quality of urban life \& environmental sustainability studies: future linkage opportunities. Habitat Int 45:47-52

Marshall A (1920) Principles of economics. MacMillan, London

Martin JC, Mendoza C, Roman C (2017) A DEA travel-tourism competitiveness index. Soc Indic Res 130(3):937-957

Matlovičová K, Matlovič R, Mušinka A Židová A (2012) The Roma population in Slovakia. Basic characteristics of the Roma population with emphasis on the spatial aspects of its differentiation. In: Penczes J, Radics Z, (Eds) 2012. Roma population on the peripheries of the Visegrad countries. Spatial trends and social challenges, Didakt, Debrecen (HU)

Meijers E (2007) From central place to network model: theory and evidence of a paradigm change. Tijdschr Econ Soc Geogr 98(2):245-259

Michálek A (2005) Concentration and attributes of poverty in the Slovak Republic at a local level. Geografický Časopis 57(1):3-22

Montalto V, Moura CJT, Langedijk S, Saisana M (2019) Culture counts: an empirical approach to measure the cultural and creative vitality of European cities. Cities 89:167-185

Morais P, Camanho AS (2011) Evaluation of performance of European cities with the aim to promote quality of life improvements. Omega 39:398-409

Neal ZP (2011) From central places to network bases: a transition in the US urban hierarchy, 1900-2000. City Community 10(1):49-75

Newport F (2018) Americans big on idea of living in the country, Gallup. Available online at. https://news. gallup.com/poll/245249/americans-big-idea-living-country.aspx

Niemesh GT, Shester KL (2020) Racial residential segregation and black low birth weight, 1970-2010. Reg Sci Urban Econ 83, 103542

OECD [Organization for Economic Cooperation and Development] (2008) Handbook on constructing composite indicators: methodology and user guide. Paris: OECD Publications No. 56327/2008. Available online at https://www.oecd.org/sdd/42495745.pdf.

OECD [Organization for Economic Cooperation and Development] (2015) Ageing in cities., OECD Publishing, Paris

Patti D, Polyák L (2017) Funding the cooperative city: community finance and the economy of civic spaces. Cooperative City Books, Vienna 
Pittini A, Koessl G, Dijol J, Lakatos E, Ghekiere L (2017) The state of housing in the EU 2017-a housing Europe review. Housing Europe, the European Federation of Public, Cooperative and Social Housing, Brussels. Available online at http://www.housingeurope.eu/file/614/download

Plaček M, Ochrana F, Půček MJ, Nemec J (2020) The fiscal decentralization in Slovakia. In: Plaček M, Ochrana F, Půček MJ, Nemec J (eds) Fiscal decentralization reforms: Public administration, governance and globalization. Springer, Cham

Podmanická Z (2011) Population ageing in the Slovak Republic in the context of urban-rural dichotomy. Forum Statisticum Slovacum 7(6):149-154

Requena F (2016) Rural-urban living and level of economic development as factors in subjective well-being. Soc Indic Res 128(2):693-708

Rochovská A, Rusnáková J (2018) Poverty, segregation and social exclusion of Roma communities in Slovakia. Bulletin Geograp Socio-Econ Series 42(42):195-212

Romein A, Trip JJ (2012) Theory and practice of the creative city thesis: experiences Amsterdam and Rotterdam. In: van Geenhuizen M, Nijkamp P (eds) Creative knowledge cities. Edward Elgar, Cheltenham

Růžička M (2012) Continuity or rupture? Roma/Gypsy communities in rural and urban environments under post-socialism. J Rural Stud 28(2):81-88

Sánchez-Zamora P, Gallardo-Cobos R, Ceña-Delgado F (2014) Rural areas face the economic crisis: analyzing the determinants of successful territorial dynamics. J Rural Stud 35:11-25

Scholten L, Schuwirth N, Reichert P, Lienert J (2015) Tackling uncertainty in multi-criteria decision analysis—an application to water supply infrastructure planning. Eur J Oper Res 245(1):243-260

Shekar S, Xiong H (2008) Encyclopedia of GIS. Springer, New York

Shwartz M, Burges JF, Zhu J (2016) A DEA based composite measure of quality and its associated data uncertainty interval for health care provider profiling and pay-for-performance. Eur J Oper Res 253(2):498-502

Silva LT (2015) Environmental quality health index for cities. Habitat Int 45:29-35

Sumity A, Raminder K (2018) Quality of life (QOL) of people living with substance users in urban and rural community of Delhi. Current Med Res Prac 8(3):96-99

Thiede BC, Lichter DT, Slack T (2018) Working, but poor: the good life in rural America? J Rural Stud 59:183-193

Tibshirani R, Walther G, Hastie T (2001) Estimating the number of clusters in a data set via the gap statistic. J Roy Stat Soc B 63(2):411-423

Toma L, Mathijs E (2007) Environmental risk perception, environmental concern and propensity to participate in organic farming programmes. J Environ Manage 83(2):145-157

Torre A, Wallet F (2016) Regional development in rural areas: analytical tools and public policies. Springer, New York

United Nations (2018) The world's cities in 2018 - data booklet. Department of Economic and Social Affairs, Population Division, New York. Available online at https://www.un.org/en/events/citiesday/ assets/pdf/the_worlds_cities_in_2018_data_booklet.pdf

Valente RR, Berry BJL (2016) Dissatisfaction with city life? latin America revisited. Cities 50:62-67

Velšic M (2017) Young people and risks of extremism: research study, Institute for Public Affairs, Bratislava. Available online at http://www.ivo.sk/buxus/docs//publikacie/subory/Mladi_a_rizika_extremizmu.pdf

Vollet D (2002) Multifonctionnalité et territoires. In: Vollet D (ed) Multifonctionnalité et territoires : justification et modalités de la territorialisation des politiques publiques. Cemagref, Paris

Ward N, Brown DL (2009) Placing the rural in regional development. Reg Stud 43(10):1237-1244

Winters JV, Li Y (2017) Urbanisation, natural amenities and subjective well-being: evidence from US counties. Urban Studies 54(8):1956-1973

Yang Z, Pan Y (2020) Are cities losing their vitality? Exploring human capital in Chinese cities. Habitat Int 96, 102104

Yang G, Shen W, Zhang D, Liu W (2014) Extended utility and DEA models without explicit input. J Oper Res Soc 65(8):1212-1220

Yekta AP, Kordrostami S, Amirteimoori A, Matin RK (2018) Data envelopment analysis with common weights: the weight restriction approach. Math Sci 12:129-203

Yin X, Chen J, Li J (2019) Rural innovation system: revitalize the countryside for a sustainable development. J Rural Stud in Press. https://doi.org/10.1016/j.jrurstud.2019.10.014

Young FW (1981) Quantitative analysis of qualitative data. Psychometrika 46(4):357-388 
Publisher's Note Springer Nature remains neutral with regard to jurisdictional claims in published maps and institutional affiliations.

\section{Authors and Affiliations}

\section{Martin Bod'a ${ }^{1,2,3}$ (D) David Cole ${ }^{1}$ (D) Mária Murray Svidroňová ${ }^{1,4}$ (D) Jolana Gubalová ${ }^{1}$}

David Cole

david.cole@umb.sk

Mária Murray Svidroňová

maria.murraysvidronova@umb.sk

Jolana Gubalová

jolana.gubalova@umb.sk

1 Faculty of Economics, Matej Bel University in Banská Bystrica, Tajovského 10, 97590 Banská Bystrica, Slovakia

2 Faculty of Social and Economic Studies, Jan Evangelista Purkyně University in Ústí nad Labem, Pasteurova 1, 40096 Ústí nad Labem, Czechia

3 Faculty of Natural Sciences, Jan Evangelista Purkyně University in Ústí nad Labem, Pasteurova 15, 40096 Ústí nad Labem, Czechia

4 Faculty of Economics and Administration, Masaryk University in Brno, Lipová 41a, 60200 Brno, Czechia 